\title{
Antimelanogenic activities of piperlongumine derived from Piper longum on murine B16F10 melanoma cells in vitro and zebrafish embryos in vivo: its molecular mode of depigmenting action
}

\author{
Hwang-Ju Jeon, Kyeongnam Kim, Yong-Deuk Kim and Sung-Eun Lee
}

\begin{abstract}
In this study, the antimelanogenic activity of piperlongumine in murine B16F10 melanoma cells and zebrafish was investigated, and its mode of antimelanogenic action was elucidated using quantitative reverse transcription-polymerase chain reaction. A melanocyte-stimulating hormone (a-MSH, $200 \mathrm{nM})$ was used to induce melanin production in B16F10 melanoma cells, and kojic acid (200 $\mu$ M) was used as a positive control. Piperlongumine had no inhibitory effects on cell growth at the treated concentrations ( 3 and $6 \mu \mathrm{M})$, and it significantly reduced total melanin production. Piperlongumine decreased the expression of Mitf, Tyr, Trp-1, and Trp-2 and tyrosinase activity was also dramatically reduced by the piper amide addition under a-MSH treatment. With these findings, zebrafish embryos were used to confirm antimelanogenic activity of piperlongumine, and it showed the potent antimelanogenic activity at the concentration of $1 \mu \mathrm{M}$. Altogether, piperlongumine has potent antimelanogenic activity, and these results support it as a candidate for natural depigmentation agent in a cosmetic and pharmaceutical industries.
\end{abstract}

Keywords: Piperlongumine, Antimelanogenic activity, B16F10 melanoma cell, Zebrafish embryos

\section{Introduction}

Protecting human skin from melanogenesis has been studied in both the cosmetic and pharmaceutical industries to identify natural products with antimelanogenetic activity [1-3]. Arbutin and kojic acid are representative antimelanogenic agents that are currently used in cosmetics and continue to be studied in the laboratory $[4,5]$. Recently, a $2 \%$ arbutin-containing hydrogel mask (arbutin mask) has been developed to treat melasma, and after using of the arbutin mask for 8 weeks, the results of the Melasma Area and Severity Index decreased in the arbutin mask group without adverse reactions in female volunteers [5]. Kojic acid also has been introduced in cosmetic industry with antityrosinase activity [6]. Its

*Correspondence: selpest@knu.ac.kr

School of Applied Biosciences, Kyungpook National University, Daegu 41566, Republic of Korea irritancy and release property in gels and multiple emulsion cream were studied, and the authors found insignificant differences between formulations [7].

Although arbutin and kojic acid are popular in the cosmetic industry, several reports have found safety issues when these chemicals are used in pharmaceutical products [8-10]. Arbutin has remained in use in the cosmetic industry, but since 2001, other hydroquinones have not been used in skin-lightening formulations in the European Union [9]. Kojic acid has been classified as a group 3 carcinogen since Burnett et al. [8] reported animal studies that showed tumor promotion and weak carcinogenicity. In response to these results, the cosmetic industry has continued to identify and develop new depigmenting agents to replace the currently used agents.

Natural products are resources to find depigmenting agents with antimelanogenic properties. Plant extracts that have been suggested to possess antimelanogenic 
activity include Alnus cordata stem bark extract, Momordica charantia methanol extract, and the ethyl acetate fraction of Calendula officinalis flowers [1113]. Single compounds isolated from natural sources are also candidates to replace arbutin and kojic acid in efficacy comparison studies. Coumaric acid, loratadine, and luteolin 7-sulfate have been studied for their antimelanogenic activities [14-16].

Piperlongumine (PL), also known as piplartine (Fig. 1), has been well documented for its biological activities against various human diseases, including digestive system cancer [17], colorectal cancer [18], breast cancer [19], rheumatoid arthritis [20], and platelet aggregation [21]. PL has been isolated from Piper plants, especially the roots of Piper longum [22], and has been developed for formulation in nanofiber mats that are used in PL-eluting gastrointestinal stents to treat cholangiocarcinoma [23]. However, with our knowledge an antimelanogenic property of PL and a molecular mode of action have not been reported in murine B16F10 cells in vitro or zebrafish in vivo. Using zebrafish model, protein expressions in zebrafish are similar to murine cell lines, then this in vivo system can be used for examining antimelanogenic active compounds in replacement of mouse or rats [24]. Zebrafishes possess melanin biosynthesis system via SOX10, which regulates the transcriptional factor known as microphthalmia-associated transcription factor, tyrosinase, tyrosinase-related protein-1 (TRP-1), and TRP-2 [25].

In this study, we investigated the effect of PL on melanin production in a murine B16F10 cell, and examined the molecular mode of its antimelanogenic property using the same cell line. Finally, the inhibitory effects of
PL on melanin generation were evaluated in vivo using zebrafish embryos.

\section{Materials and methods \\ Chemicals and reagents}

Piperlongumine, $\alpha$-melanocyte-stimulating hormone $(\alpha-\mathrm{MSH})$, and kojic acid (KA) were purchased from Sigma-Aldrich (St. Louis, MO, USA, Fig. 1a). An MTS assay kit, the CellTiter 96 Aqueous One Solution, was obtained from Promega (Madison, WI, USA). Other chemicals were obtained in the highest grade used in experimental procedure.

\section{Cell culture and viability test}

The B16F10 mouse melanoma cell line was obtained from the American Type Culture Collection (ATCC, VA, USA). Cells were cultured in Dulbecco's modified Eagles medium (GE Healthcare, IL, USA) with $10 \%$ fetal bovine serum at $37{ }^{\circ} \mathrm{C}$, in humidified air with $5 \% \mathrm{CO}_{2}$. Cells were subcultured every 2 days with at a ratio of 1:8.

To determine the cytotoxicity of PL to the B16F10 melanoma cell line, MTS assays were performed. Cells were plated into 96-well plates at $2 \times 10^{3}$ cells/well and incubated $24 \mathrm{~h}$ for recovery. After recovery, the culture media was replaced with or without PL for $48 \mathrm{~h}$, and then $20 \mu \mathrm{l}$ of MTS assay solution was added to each well and incubated for additional $4 \mathrm{~h}$. The optical density of each well at $490 \mathrm{~nm}$ was measured with a Multiskan GO microplate reader (Thermo Scientific, Waltham, MA, USA).

\section{Determination of melanin content}

B16F10 melanoma cells were cultured in 6-well plates with phenol-free DMEM supplemented with $10 \%$ fetal bovine serum to determine the melanin content. After

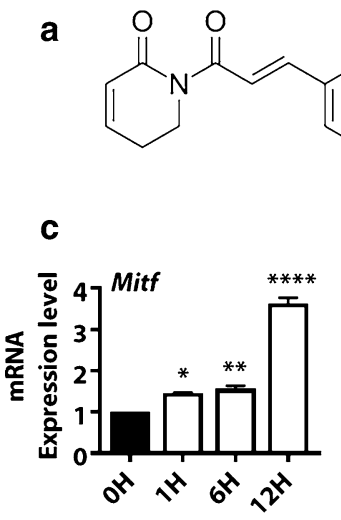<smiles>COc1cccc2c1OCCO2</smiles>
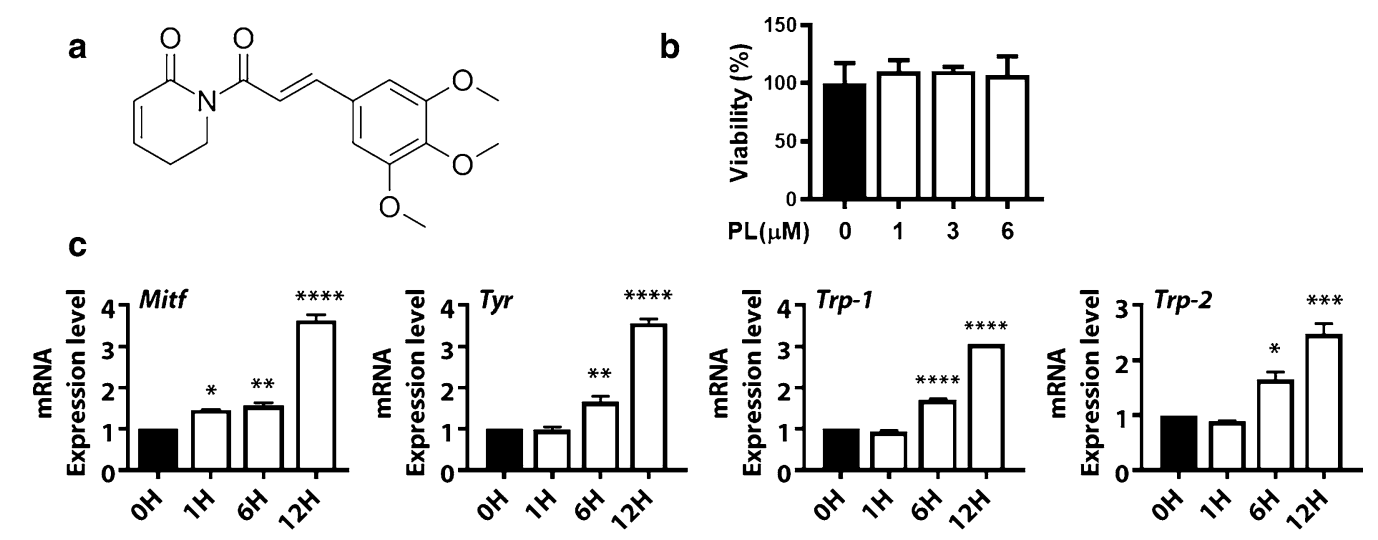

Fig. 1 a Structure of piperlongumine; b viability of murine B16F10 cells in response to increasing concentrations of piperlongumine; c expression levels after treatment of a-melanocyte stimulating hormone. Mitf, microphthalmia associated transcription factor; Tyr, tyrosinase; Trp-1, tyrosinase-related protein 1 ; and Trp-2, tyrosinase-related protein 2 . Significant differences are expressed by the symbols $*^{*}, *^{*}, *^{* *}$, and ${ }^{* * * *}$ as $p<0.05, p<0.01, p<0.001$, and $p<0.0001$, respectively 
$24 \mathrm{~h}$ of recovery, cells were treated with or without $200 \mathrm{nM} \alpha-\mathrm{MSH}$ and PL, followed by $72 \mathrm{~h}$ incubation. After incubation, cells were harvested with $1 \mathrm{~N} \mathrm{NaOH}$ containing $10 \%$ DMSO and then heated at $80{ }^{\circ} \mathrm{C}$ for $1 \mathrm{~h}$ to dissolve melanin. The absorbance of the heated solution and media at $400 \mathrm{~nm}$ was measured. The total melanin content was normalized to the concentration of total protein.

\section{RNA isolation and qRT-PCR}

Total RNA was extracted from B16F10 cells using Trizol solution (Qiagen, Valencia, CA, USA). To quantify changes in mRNA levels in B16F10 cells, $2 \mu \mathrm{g}$ of total RNA was converted into cDNA with a first-strand cDNA synthesis kit (Thermo Scientific, Waltham, MA, USA) according to manufacturer's protocols. A Qiagen Rotor-Gene Q Real-Time PCR instrument (Qiagen) and Rotor-Gene SYBR Green PCR kit were used to quantify the target mRNA level, including Gapdh, Mitf, Tyr, Trp1 , and Trp-2. Sequences of primers used in this study are listed in Table 1.

\section{Intracellular tyrosinase activity assay}

Intracellular tyrosinase activity was determined according to a modified version of a previously described method [26]. Briefly, B16F10 cells were harvested with lysis buffer containing a proteinase inhibitor, and then $20 \mu \mathrm{l}$ of lysate and $80 \mu \mathrm{l}$ of $2 \mathrm{mM} \mathrm{L}$-DOPA were added to each well of a 96-well plate and incubated for $2 \mathrm{~h}$ at $37^{\circ} \mathrm{C}$. The amount of oxidated L-DOPA was determined using a Multiskan GO microreader. Absorbance at $475 \mathrm{~nm}$ was measured, and protein concentration was normalized to total protein.

\section{Fish care and PL treatment}

Wild-type (WT) zebrafish were provided by Professor Tae-Lin Huh from the School of Life Science and Biotechnology, Kyungpook National University, Daegu, Republic of Korea. To obtain zebrafish embryos, females and males were crossed at a 1:2 ratio in a breeding chamber overnight at $26 \pm 1{ }^{\circ} \mathrm{C}$. The group of zebrafish embryos

Table 1 Primers lists used in this study for melanogenesis related genes murine melanoma cells

\begin{tabular}{lll}
\hline Gene & Forward & Reverse \\
\hline Gapdh & GGTTGTCTCCTGCGACTTCA & TGGTCCAGGGTTTCTTACTCC \\
Tyr & TCTTCACCATGCTTTTGTGG & ATAGGTGCATTGGCTTCTGG \\
Mitf & CATCATCAGCCTGGAATCAA & TCAAGTTTCCAGAGACGGGT \\
Trp-1 & TGGTCTGTGAATCCTTGGAA & CATTTCCAGCTGGGTTTCTC \\
Trp-2 & CGTGCTGAACAAGGAATGC & CGAAGGATATAAGGGCCACTC \\
\hline
\end{tabular}

was obtained with a total fertilization rate of $\geq 80 \%$ and used for experiments. Twelve embryos were treated with PL or kojic acid at $6 \mathrm{~h}$ post-fertilization (hpf), and chorion were removed at $24 \mathrm{hpf}$. PL and kojic acid were dissolved in dimethyl sulfoxide (DMSO), and DMSO was used as vehicle control up to $0.1 \%(\mathrm{v} / \mathrm{v})$. Embryos were treated with PL $(0,0.5,1$, and $2 \mu \mathrm{M})$ and $8 \mathrm{mM}$ kojic acid in 6-well plates containing $5 \mathrm{ml}$ of $\mathrm{E} 3$ medium (consisting of $5 \mathrm{mM} \mathrm{NaCl}, 0.17 \mathrm{mM} \mathrm{KCl}, 0.33 \mathrm{mM} \mathrm{CaCl}_{2}$, and $0.33 \mathrm{mM} \mathrm{MgSO}_{4}$ ) with a $\mathrm{pH}$ value of 7.2 for $72 \mathrm{hpf}$. All experiments were performed in triplicate.

\section{PL effect on melanogenic activity in zebrafish embryos}

Embryos at $72 \mathrm{hpf}$ were photographed in lateral and dorsal view to compare the pigmentation phenotype between groups using a BX53 upright microscope with a DP80 color camera (Olympus Life Science Solutions, Waltham, MA). After monitoring the melanogenic inhibitory effect, zebrafish embryos were collected in CETi lysis buffer (TransLab, Daejeon, Korea) and homogenized using a pencil-type homogenizer. Embryo lysates were centrifuged at $13,000 \mathrm{rpm}$ for $10 \mathrm{~min}$ to separate protein and precipitated melanin. The melanin precipitate was resuspended with $1 \mathrm{M} \mathrm{NaOH}$ at $95{ }^{\circ} \mathrm{C}$ for $1 \mathrm{~h}$ and measured at $400 \mathrm{~nm}$ in triplicate. The melanin contents of zebrafish embryos were normalized to the total protein concentration measured in the same embryo.

\section{Statistical analysis}

All statistical analyses were performed using GraphPad Prism 8.0 software. The statistical significance of differences was determined by multiple comparisons of Turkey's test and multiple comparisons were analyzed using one-way ANOVA. All data are presented as means \pm standard error of the mean (S.E.M.). The value of $p<0.05$ is considered as statistical significance.

\section{Results and discussion}

Melanin pigments can be consisted of three different types of molecules such as pheomelanin, eumelanin and neuromelanin. Among them, eumelanin production is related to the involvement of three key enzymes as tyrosinase (TYR), tyrosine-relate protein-1 (TRP-1), and tyrosine-related protein-2 (TRP-2), referring to tyrosine conversion to construct melanin pigments [27]. Melanin synthesis or melanogenesis can be initiated by various paracrine cytokines such as $\alpha$-melanocyte-stimulating hormone $(\alpha-M S H)$, which is used in this study as well as other studies $[28,29]$. Other cytokines as stem cell factor (SCF), endothelin-1, and nitric oxide have been known as triggers of melanogenesis under the exposure of UV-B irradiation [30-32]. 
These factors enhance melanin synthesis via diverse cell signaling pathway by inducing the expression of pigment-related genes as microphthalmia-associated transcription factor (Mitf), Tyr, Trp-1, and Trp-2. Therefore, inhibition of Mitf gene expression, known as a primary up-regulator of melanin biosynthesis, has been known as a major target site of antimelanogenic agents [15, 16]. Other antimelanogenic routes are related to reduce the mitogen-activated protein kinase (MAPK) cascade via decreasing phosphorylation of extracellular-signalregulated kinase 1/2 (ERK1/2), and to decrease guanylyl cyclase expression via down-regulation of the production of cGMP [30, 33, 34].

In our study, PL does not suppress cell growth until the concentration tested reached $6 \mu \mathrm{M}$ (Fig. 1b). $\alpha$-Melanocyte-stimulating hormone $(\alpha-\mathrm{MSH}, 200 \mathrm{nM})$ upregulates four genes involved in melanin biosynthesis in the B16F10 cell line: mitf, tyr, trp-1, and trp-2, which encode microphthalmia-associated transcription factor, tyrosinase, tyrosine-related protein 1 , and tyrosinerelated protein 2 , respectively (Fig. 1c). The expression of these four genes increases over time until $12 \mathrm{~h}$. Therefore, the incubation time for each experiment in our study was set to $12 \mathrm{~h}$.

$\alpha-\mathrm{MSH}$ increases the intracellular production of melanin approximately threefold and extracellular melanin increases approximately twofold compared with the control group (Fig. 2). $\alpha-\mathrm{MSH}$ increases the total melanin production by approximately 1.8 -fold relative to control cells (Fig. 2). Kojic acid (200 $\mu \mathrm{m})$, a positive control for antimelanogenic activity, with $\alpha$-MSH decreased melanin production relative to cells treated with $\alpha-\mathrm{MSH}$ alone, and the decrease in response to kojic acid was significant (Fig. 2). Two concentrations ( 3 and $6 \mu \mathrm{M}$ ) of PL were used with $\alpha-\mathrm{MSH}$, and intracellular melanin content decreases in a concentration-dependent manner (Fig. 2). Interestingly, extracellular melanin content is dramatically reduced compared with the control group, $\alpha-\mathrm{MSH}-$ treated group, and kojic acid-treated group (Fig. 2). Similarly, PL decreases melanin production to a greater extent than seen in the control, $\alpha-\mathrm{MSH}$-treated group, and kojic acid-treated group (Fig. 2). In addition to this

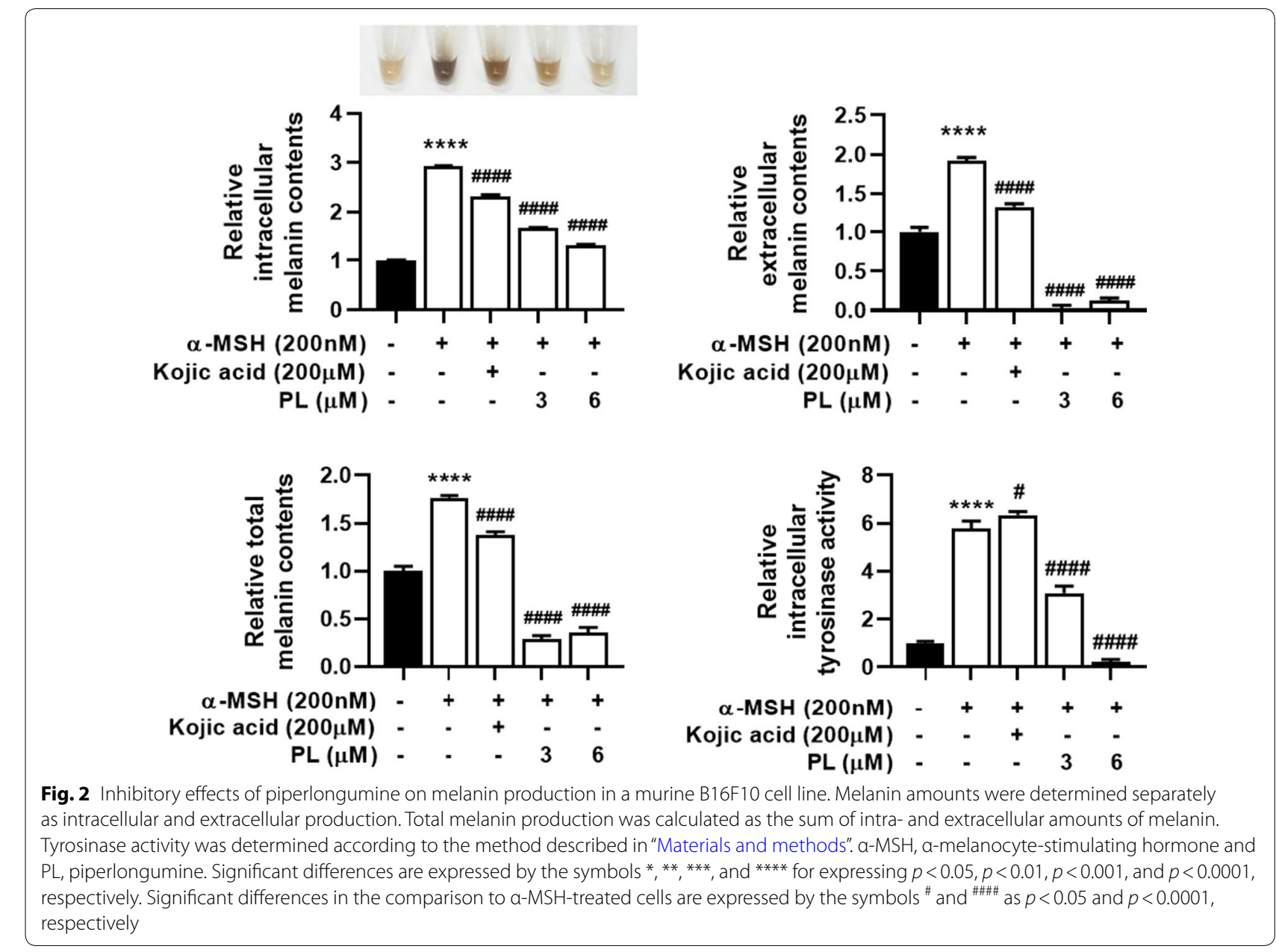


regard, kojic acid does not inhibit intracellular tyrosinase activity at the treated concentration $(200 \mu \mathrm{M})$, while PL suppresses the enzyme activity in a concentrationdependent manner (Fig. 2).

To elucidate the mode of antimelanogenic action, we show that kojic acid and PL inhibit the expression of Mitf, Tyr, Trp-1, and Trp-2 (Fig. 3). Using these results, we demonstrated that PL exhibited potent antimelanogenic activity when compared to kojic acid. Therefore, PL exhibit its antimelanogenic activity via down-regulation of Mitf gene expression in B16F10 melanoma cells, suppressing expression of other three genes responsible for expressing TYR, TRP- 1 and TRP-2 proteins.

For confirming antimelanogenic activity of PL using zebrafish embryos, Kojic acid shows its antimelanogenic activity at the concentration of $8 \mathrm{mM}$, while antimelanogenic activity of $\mathrm{PL}$ is initiated from the concentration level of $1 \mu \mathrm{M}$ (Fig. 4; Additional file 1: Fig. S1). However, a developmental disorder on zebrafish embryos is observed from the contraction of $2 \mu \mathrm{M}$ of PL (Fig. 4). Therefore, we found antimelanogenic activity of PL on zebrafish embryos, but we should consider PL's toxicity on the zebrafish embryos.

Other studies have shown antimelanogenic activities of natural products using various cell lines and ex vivo and in vivo experiments. Recently, $p$-coumaric acid was shown to exhibit antimelanogenic activity by inhibiting human tyrosinase, and the effect was stronger than those of arbutin or kojic acid [14]. In a review, $p$-coumaric acid was reported to exert inhibitory effects on melanin production in murine melanoma cell lines and human epidermal melanocytes, including a 3D-skin model.

Luteolin-7-sulfate also showed unique inhibitory activity on melanin production via suppressing tyrosinase expression mediated by CREB and MITF [15]. These authors demonstrated that luteolin-7-sulfate exerted inhibitory effects at various concentrations ranging from 3 to $30 \mu \mathrm{M}$ with $100 \mathrm{nM}$ of $\alpha-\mathrm{MSH}$ on murine B17F10 melanoma cells, whereas the concentration of arbutin needed for antimelanogenic activity ranged from 100 to $1000 \mu \mathrm{M}$. The antimelanogenic activity in luteolin-7-sulfate-treated cells and arbutin-treated cells occurred in a concentration-dependent manner.
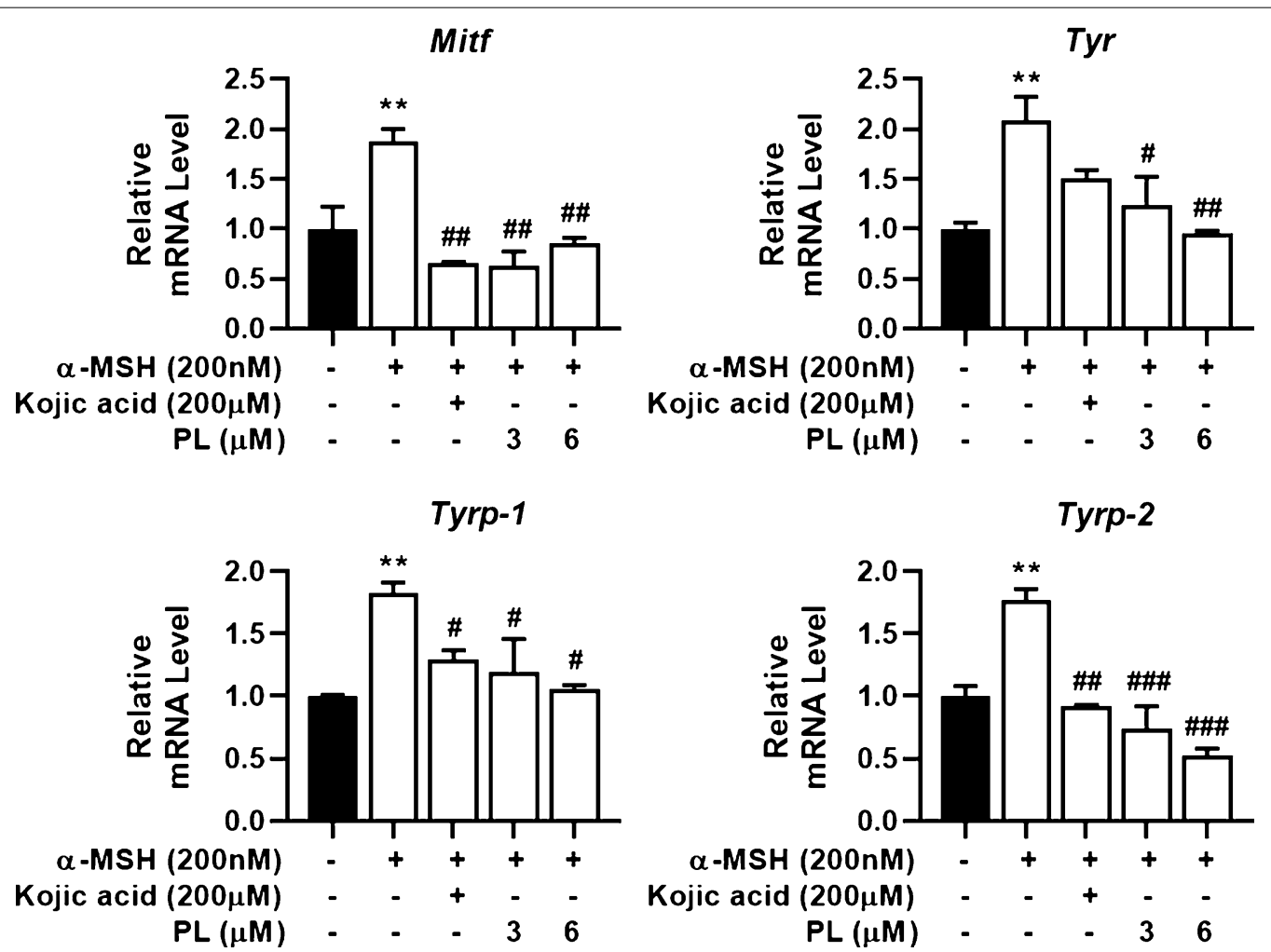

Fig. 3 Inhibitory effects of piperlongumine on four genes involved in melanin biosynthesis in a murine B16F10 cell line using RT-qPCR. a-MSH, a-melanocyte stimulating hormone; PL, piperlongumine; Mitf, microphthalmia associated transcription factor; Tyr, tyrosinase; Trp-1, tyrosinase-related protein 1; and Trp-2, tyrosinase-related protein 2. Significant differences are expressed by the symbols $*^{* * *}, *^{* *}$, and ${ }^{* * *}$ for expressing $p<0.05, p<0.01, p<0.001$, and $p<0.0001$, respectively. Significant differences in the comparison to a-MSH-treated cells are expressed by the symbols" \#\#,\#\#, and ${ }^{\# \# \# ~ a s ~} p<0.05, p<0.01, p<0.001$, and $p<0.0001$, respectively 

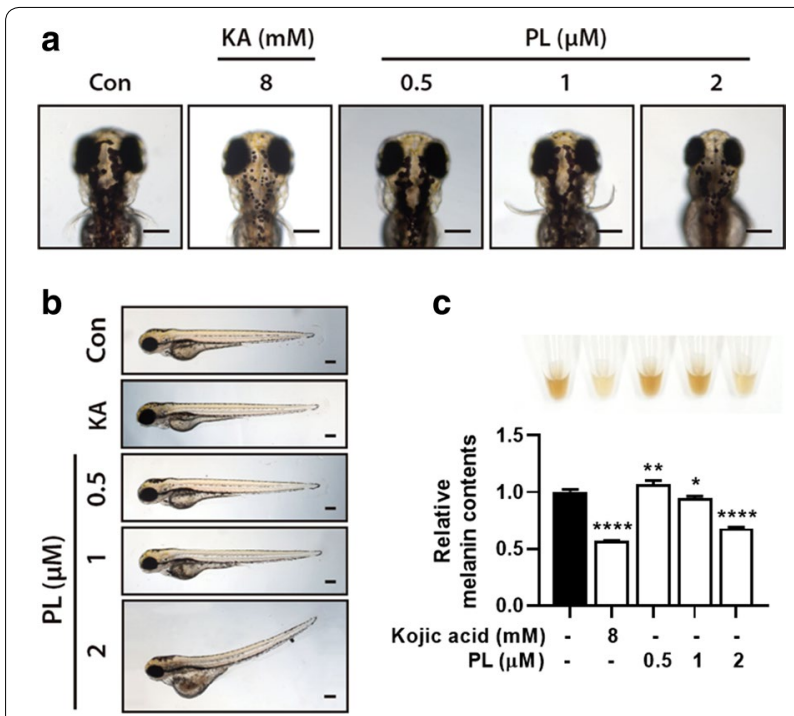

C

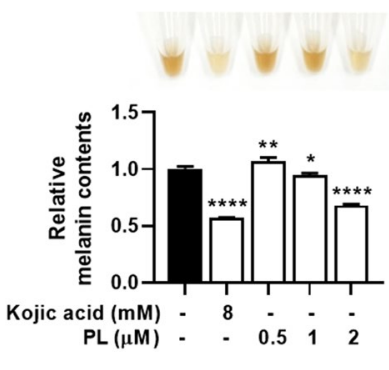

Fig. 4 Inhibitory effects of piperlongumine (PL) on melanin production in zebrafish embryos (Danio rerio). a Images of depigmentation in the head of zebrafish embryos after treatment with PL. Kojic acid (KA, 8 mM) was used as a positive control. b Images of the development of zebrafish embryos to larvae after chemical treatment at embryo stages. PL exhibits potent developmental toxicity with spine curvature at $2 \mu \mathrm{M}$. c Melanin production in zebrafish embryos after treatment with the indicated chemicals. Con, control. Significant differences are expressed by the symbols ${ }^{*},{ }^{* *}, * * *$ and ${ }^{* * *}$ as $p<0.05, p<0.01, p<0.001$, and $p<0.0001$, respectively

Because luteolin 7-sulfate showed a strong inhibitory effects on tyrosinase activity induced by $\alpha-\mathrm{MSH}$ and forskolin, mRNA expression of tyr and mitf was also found to be downregulated when luteolin 7-sulfate was added to cells with forskolin [15]. In addition, Piper amides have been found to have antimelanogenic activity through the regulation of the TRPM1 calcium channel [35]. A recent study using HepG2 cells reported that PL is a potent activator of AMP-activated kinase [36]. PL also downregulated ERK signaling in renal carcinoma cells [37]. Therefore, PL may be expected to inhibit MITF protein phosphorylation since [8]-gingerol inhibited MITF activation via inhibition of ERK phosphorylation [35]. As we found in our study, the Mitf gene was downregulated, inferring that MITF protein expression would be decreased in response to PL treatment (Fig. 3). This lower expression of Mitf gene leads to lower expression of Tyr, Trp-1, and Trp-2 (Fig. 3).

As we found antimelanogenic activity of PL using zebrafish embryos (Fig. 4), Lee et al. [38] used zebrafish model to isolate active compounds from silkworm droppings (Bombyx mori) as dehydrovomifolial and citroside A. Interestingly, in our study, PL showed a potent depigmenting effect at the very low level as $1 \mu \mathrm{M}$ when compared to the positive control compound, kojic acid

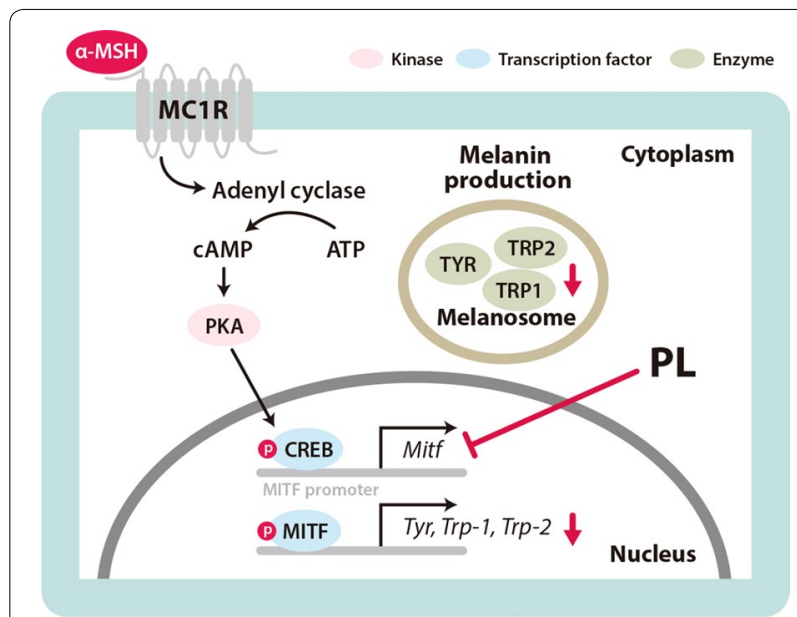

Fig. 5 Schematic diagram of melanin production and the inhibition site of piperlongumine

$(8 \mathrm{mM})$ on zebrafish embryos. However, this in vivo experiment using zebrafish embryos confirmed two important things that PL had strong antimelanogenic activity and exhibited high developmental toxicity on fish from $2 \mu \mathrm{M}$ of PL addition (Fig. 4). Further studies should be conducted for assessing fish toxicity level of PL and its mode of toxic effect using zebrafish embryos and adults.

Schematic diagram of melanin production through a-MSH induction and the inhibition site of PL on melanin biosynthesis is depicted in Fig. 5.

\section{Supplementary information}

Supplementary information accompanies this paper at https://doi. org/10.1186/s13765-019-0468-7.

Additional file 1: Fig. S1. Inhibitory effects of kogic acid on melanin production in zebrafish embryos (Danio rerio). (a) Dorsal view of depigmentation in the head of zebrafish embryos after treatment with kojic acid (1,4, and $8 \mathrm{mM}$ ) for $72 \mathrm{~h}$ post fertilization (hpf). (b) Relative melanin contents of zebrafish embryos after exposure to various concentrations of kogic acid. Significant differences are expressed by the symbols ${ }^{*},{ }^{*},{ }^{* * *}$, and ${ }^{* * * *}$ as $p<0.05, p<0.01, p<0.001$, and $p<0.0001$, respectively.

\section{Acknowledgements}

Not applicable.

\section{Authors' contributions}

$\mathrm{H}-\mathrm{J} J$ and S-EL designed experiments as well as wrote the draft manuscript. $\mathrm{H}-\mathrm{J} J$ and $\mathrm{KK}$ conducted the experiments. H-JJ, Y-DK and S-EL conducted result analysis and interpretation. $\mathrm{H}-J \mathrm{~J}, \mathrm{KK}$ and $\mathrm{S}$-EL inspired the overall work and revised the final manuscript. All authors read and approved the final manuscript.

\section{Funding}

This study was supported by Kyungpook National University Research Fund (2017).

\section{Availability of data and materials}

The datasets used and/or analyzed during the current study are available from the corresponding author on reasonable request. 


\section{Competing interests}

The authors declare that they have no competing interests.

Received: 6 September 2019 Accepted: 14 October 2019 Published online: 30 October 2019

\section{References}

1. Heriniaina RM, Dong J, Kalavagunta PK, Wu HL, Yan DS, Shang J (2018) Effects of six compounds with different chemical structures on melanogenesis. Chin J Nat Med 16:766-773

2. Huang HC, Chou YC, Wu CY, Chang TM (2013) [8]-Gingerol inhibits melanogenesis in murine melanoma cells through down-regulation of the MAPK and PKA signal pathways. Biochem Biophys Res Commun 438:375-381

3. Venkatasamy R, Faas L, Young AR, Raman A, Hider RC (2004) Effects of piperine analogues on stimulation of melanocyte proliferation and melanocyte differentiation. Bioorg Med Chem 12:1905-1920

4. Baik JHLM (2000) Antimelanogenic effects of arbutin. Korean J Dermato 38:1303-1308

5. Han TYSI, Jang WS, Chang HS, Kim JH, Sim YH, Kim DH, Kim BJ, Kim MN, Lee HK, Son SJ, Choi BS (2011) Efficacy of hydrogel mask with 2\% arbutin for melisma. Korean J Dermatol 49:210-216

6. Park YLJ, Park J, Park D (2003) Effects of kojic acid, arbutin and vitamin C on cell viability and melanin synthesis in B16BL6 cells. Korean J Dermatol 29:151-167

7. Yu SUPE, Choi YW (1998) Drug release characteristics and skin irritancies of topical and multiple emulsion creams containing kojic acid. J Korean Pharm Sci 28:87-92

8. Burnett CL, Bergfeld WF, Belsito DV, Hill RA, Klaassen CD, Liebler DC, Marks JG Jr, Shank RC, Slaga TJ, Snyder PW, Andersen FA (2010) Final report of the safety assessment of kojic acid as used in cosmetics. Int J Toxicol 29:244S-273S

9. O'Donoghue JL (2006) Hydroquinone and its analogues in dermatology - a risk-benefit viewpoint. J Cosmet Dermatol 5:196-203

10. Ota Y, Imai T, Onose J, Takami S, Cho YM, Hirose M, Nishikawa A (2009) A 55-week chronic toxicity study of dietary administered kojic acid (KA) in male F344 rats. J Toxicol Sci 34:305-313

11. Park SH, Yi YS, Kim MY, Cho JY (2019) Antioxidative and antimelanogenesis effect of Momordica charantia methanol extract. Evid Based Complement Altern Med 2019:5091534

12. Smeriglio A, D'Angelo $V$, Denaro M, Trombetta D, Raimondo FM, Germano MP (2019) Polyphenol characterization, antioxidant and skin whitening properties of Alnus cordata stem bark. Chem Biodivers. https://doi. org/10.1002/cbdv.201900314

13. Xuan SH, Park YM, Park SN (2019) Antimelanogenic and antimigration properties of the ethyl acetate fraction of Calendula officinalis flowers on melanoma cells. Photochem Photobiol 95:860-866

14. Boo YC (2019) p-Coumaric acid as an active ingredient in cosmetics: a review focusing on its antimelanogenic effects. Antioxidants 8:275

15. Lee SW, Kim JH, Song H, Seok JK, Hong SS, Boo YC (2019) Luteolin 7-sulfate attenuates melanin synthesis through inhibition of CREB- and MITF-mediated tyrosinase expression. Antioxidants 8:87

16. Moon HR, Jo SY, Kim HT, Lee WJ, Won CH, Lee MW, Choi JH, Chang SE (2019) Loratadine, an H1 antihistamine, inhibits melanogenesis in human melanocytes. Biomed Res Int 2019:5971546

17. Song $Y$, Yang H, Lin R, Jiang K, Wang BM (2019) The role of ferroptosis in digestive system cancer. Oncol Lett 18:2159-2164

18. Chen W, Lian W, Yuan Y, Li M (2019) The synergistic effects of oxaliplatin and piperlongumine on colorectal cancer are mediated by oxidative stress. Cell Death Dis 10:600

19. Chen D, Ma Y, Li P, Liu M, Fang Y, Zhang J, Zhang B, Hui Y, Yin Y (2019) Piperlongumine induces apoptosis and synergizes with doxorubicin by inhibiting the JAK2-STAT3 pathway in triple-negative breast cancer. Molecules 24:2338

20. Xiao Y, Shi M, Qiu Q, Huang M, Zeng S, Zou Y, Zhan Z, Liang L, Yang X, Xu $H(2016)$ Piperlongumine suppresses dendritic cell maturation by reducing production of reactive oxygen species and has therapeutic potential for rheumatoid arthritis. J Immunol 196:4925-4934
21. Yuan H, Houck KL, Tian Y, Bharadwaj U, Hull K, Zhou Z, Zhu M, Wu X Tweardy DJ, Romo D, Fu X, Zhang Y, Zhang J, Dong JF (2015) Piperlongumine blocks JAK2-STAT3 to inhibit collagen-induced platelet reactivity independent of reactive oxygen species. PLoS ONE 10:e0143964

22. Rajopadhye AANT, Upadhye AS (2012) Rapid validated HPTLC method for estimation of piperine and piperlongumin in root of Piper longum extract and its commercial formulation. Rev Bras Farmacogn 22:1355-1361

23. Jang HH, Park SB, Hong JS, Lee HL, Song YH, Kim J, Jung YH, Kim C, Kim DM, Lee SE, Jeong YI, Kang DH (2019) Piperlongumine-eluting gastrointestinal stent using reactive oxygen species-sensitive nanofiber mats for inhibition of cholangiocarcinoma cells. Nanoscale Res Lett 14:58

24. Lajis AFB (2018) A zebrafish embryo as an animal model for the treatment of hyperpigmentation in cosmetic dermatology medicine. Medicina 54:35

25. Singh AP, Dinwiddie A, Mahalwar P, Schach U, Linker C, Irion U, NussleinVolhard C (2016) Pigment cell progenitors in zebrafish remain multipotent through metamorphosis. Dev Cell 38:316-330

26. Oh TI, Jung HJ, Lee YM, Lee $\mathrm{S}$, Kim GH, Kan SY, Kang H, Oh T, Ko HM, Kwak KC, Lim JH (2018) Zerumbone, a tropical ginger sesquiterpene of Zingiber officinale Roscoe, attenuates alpha-MSH-induced melanogenesis in B16F10 cells. Int J Mol Sci 19:3149

27. Park SH, Kim DS, Kim WG, Ryoo IJ, Lee DH, Huh CH, Youn SW, Yoo ID, Park KC (2004) Terrein: a new melanogenesis inhibitor and its mechanism. Cell Mol Life Sci 61:2878-2885

28. Andoh T, Akasaka C, Shimizu K, Lee JB, Yoshihisa Y, Shimizu T (2019) Involvement of alpha-melanocyte-stimulating hormone-thromboxane A2 system on itching in atopic dermatitis. Am J Pathol 189:1775-1785

29. Phacharapiyangkul N, Thirapanmethee K, Sa-Ngiamsuntorn K, Panich U, Lee $\mathrm{CH}$, Chomnawang MT (2019) Effect of sucrier banana peel extracts on inhibition of melanogenesis through the ERK signaling pathway. Int J Med Sci 16:602-606

30. Li PH, Liu LH, Chang CC, Gao R, Leung CH, Ma DL, David Wang HM (2018) Silencing stem cell factor gene in fibroblasts to regulate paracrine factor productions and enhance c-kit expression in melanocytes on melanogenesis. Int J Mol Sci 19:1475

31. Niwano T, Terazawa S, Sato Y, Kato T, Nakajima H, Imokawa G (2018) Glucosamine abrogates the stem cell factor + endothelin-1-induced stimulation of melanogenesis via a deficiency in MITF expression due to the proteolytic degradation of CREB in human melanocytes. Arch Dermatol Res 310:625-637

32. Seong NW, Oh WJ, Kim IS, Kim SJ, Seo JE, Park CE, Kim DY, Ko JW, Kim JC (2019) Efficacy and local irritation evaluation of Eriobotrya japonica leaf ethanol extract. Lab Anim Res 35:4

33. Moon KM, Jeong JW, Lee B, Kim DH, Kim HR, Woo YW, Lee EK, An HJ, Kim MJ, Choi YJ, Son SJ, Chun P, Moon HR, Chung HY (2016) Antimelanogenic activity of MHY384 via inhibition of NO-induced cGMP signaling. Exp Dermatol 25:652-654

34. Wu LC, Lin YY, Yang SY, Weng YT, Tsai YT (2011) Antimelanogenic effect of c-phycocyanin through modulation of tyrosinase expression by upregulation of ERK and downregulation of p38 MAPK signaling pathways. J Biomed Sci 18:74

35. Hwang E, Lee TH, Lee WJ, Shim WS, Yeo EJ, Kim S, Kim SY (2016) A novel synthetic Piper amide derivative NED-180 inhibits hyperpigmentation by activating the PI3K and ERK pathways and by regulating Ca2+ influx via TRPM1 channels. Pigment Cell Melanoma Res 29:81-91

36. Ryu J, Kim MJ, Kim TO, Huh TL, Lee SE (2014) Piperlongumine as a potential activator of AMP-activated protein kinase in HepG2 cells. Nat Prod Res 28:2040-2043

37. Golovine K, Makhov P, Naito S, Raiyani H, Tomaszewski J, Mehrazin R, Tulin A, Kutikov A, Uzzo RG, Kolenko VM (2015) Piperlongumine and its analogs down-regulate expression of c-Met in renal cell carcinoma. Cancer Biol Ther 16:743-749

38. Lee YR, Park JH, Castaneda Molina R, Nam YH, Lee YG, Hong BN, Baek NI, Kang TH (2018) Skin depigmenting action of silkworm (Bombyx mori L.) droppings in zebrafish. Arch Dermatol Res 310:245-253

\section{Publisher's Note}

Springer Nature remains neutral with regard to jurisdictional claims in published maps and institutional affiliations. 